\title{
Anomalous Fatigue Behavior and Fatigue-Induced Grain Growth in Nanocrystalline Nickel Alloys
}

\begin{abstract}
BRAD L. BOYCE and HENRY A. PADILLA, II
Fatigue failure due to repetitive loading of metallic devices is a pervasive engineering concern. The present work reveals extraordinary fatigue resistance in nanocrystalline (NC) alloys, which appears to be associated with the small $(<100 \mathrm{~nm})$ grain size inhibiting traditional cyclic damage processes. In this study, we examine the fatigue performance of three electrodeposited $\mathrm{NC} \mathrm{Ni-}$ based metals: Ni, Ni-0.5Mn, and Ni-22Fe (PERMALLOY). When subjected to fatigue stresses at and above the tensile yield strength where conventional coarse-grained (CG) counterparts undergo low-cycle fatigue failure $\left(<10^{4}\right.$ cycles to failure), these alloys exhibit exceptional fatigue lives (in some cases, $>10^{7}$ cycles to failure). Postmortem examinations show that failed samples contain an aggregate of coarsened grains at the crack initiation site. The experimental data and accompanying microscopy suggest that the $\mathrm{NC}$ matrix undergoes abnormal grain growth during cyclic loading, allowing dislocation activity to persist over length scales necessary to initiate a fatigue crack by traditional fatigue mechanisms. Thus, the present observations demonstrate anomalous fatigue behavior in two regards: (1) quantitatively anomalous when considering the extremely high stress levels needed to drive fatigue failure and (2) mechanistically anomalous in light of the grain growth process that appears to be a necessary precursor to crack initiation.
\end{abstract}

DOI: $10.1007 / \mathrm{s} 11661-011-0708-\mathrm{x}$

(c) The Minerals, Metals \& Materials Society and ASM International (outside the USA) 2011

\section{INTRODUCTION}

THE origins of modern understanding of metal fatigue date back to the 1830 s and 1840 s when mine conveyor chain failures in Clausthal, Germany and a catastrophic locomotive axle failure in Versailles, France were linked to repetitive cyclic loading of metal components. ${ }^{[1]}$ Since that time, researchers have been in search of metals that are either impervious or highly resistant to fatigue failure. The advent of nanocrystalline (NC) metals, ${ }^{[2]}$ with their superior strength and hardness to conventional coarse-grained (CG) counterparts, offers the possibility of a new metallurgical pathway to improved fatigue performance. ${ }^{[3-9]}$ Indeed, published literature on the fatigue performance of $\mathrm{NC}$ metals clearly demonstrates improvements in fatigue strength over CG metals. ${ }^{[10-15]}$

Aside from quantitative improvements in fatigue performance, NC metals also hold the possibility of new insight into the mechanisms responsible for traditional fatigue failure. In the recent past, studies on the monotonic strength of NC metals have not only revealed quantitative details regarding the Hall-Petch strengthening effect, ${ }^{[16-18]}$ but also led to the discovery of mechanistic transitions in dislocation behavior. For example, while individual dislocation slip is still active

BRAD L. BOYCE, Principal Member of the Technical Staff, and HENRY A. PADILLA, II, Postdoctoral Appointee, are with the Materials Science and Engineering Center, Sandia National Laboratories, Albuquerque, NM 87185-0889. Contact e-mail: blboyce@ sandia.gov

Manuscript submitted November 19, 2010.

Article published online May 3, 2011 in NC metals with a grain size in the range of 20 to 50 $\mathrm{nm},{ }^{[4,19,20]}$ there is insufficient space for the collective dislocation interaction mechanisms found in CG metals such as pileups and subgrain formation. Instead, deformation is governed by dislocation nucleation and absorption at grain boundaries. ${ }^{[19-22]}$ In large-grained metals, persistent slip bands (PSBs) are responsible for the formation of surface extrusions and intrusions, which are the precursor for fatigue crack initiation. ${ }^{[23]}$ This process requires the collective activity of many dislocations within a grain, which the literature indicates should be on the order of hundreds of nanometers in size. ${ }^{[24]}$ While other researchers have previously noted that crack initiation susceptibility typically decreases with decreasing grain size in metals, ${ }^{[25]}$ we further postulate that the persistent slip mechanism responsible for conventional fatigue crack initiation may be suppressed when the grain size is below a certain threshold, likely on the order of $100 \mathrm{~nm}$ or several hundred nanometers. This length scale threshold is between grain sizes that support collective dislocation activity and grain sizes that support individual dislocation activity. However, a survey of the available literature on the fatigue of $\mathrm{NC}$ metals reveals that fatigue failure still occurs for $\mathrm{NC}$ metals, often with nothing more than a modest improvement in performance over CG metals. ${ }^{[26,27]}$

Perhaps the explanation for the lack of dramatic improvements in fatigue performance is related to the instability of $\mathrm{NC}$ grain structures, which are known to evolve even during storage at room temperature. ${ }^{[28]}$ Previous experimental observations of $\mathrm{NC}$ grain growth during plastic deformation, ${ }^{[29,30]}$ indentation 
experiments $^{[31]}$ and as a result of fatigue loading ${ }^{[14,32]}$ warrant serious consideration. The grain growth reported by Witney et al.'s ${ }^{[14]}$ fatigue experiments on $\mathrm{NC} \mathrm{Cu}$ presumably refers to modest overall grain growth, rather than discontinuous local coarsening observed in monotonic loading experiments by Gianola et al. ${ }^{[29]}$ In addition, several numerical models predicted evolution in NC grain structures under both elastic ${ }^{[33,34]}$ and plastic ${ }^{[35-37]}$ deformation. These previous observations on room-temperature mechanically driven grain growth lead one to suspect that NC metals may evolve such coarse grain structures during fatigue loading, and that the fatigue mechanisms may be influenced more by the evolved grain structure than by the initial structure.

To investigate the relationship between deformation mechanisms and the fatigue behavior of NC metals, stress-life fatigue tests were performed on three Ni-based NC alloys with microstructural evaluation both before and after testing using focused ion beam (FIB) cross sectioning, electron backscattered diffraction (EBSD), and transmission electron microscopy (TEM).

\section{EXPERIMENTAL METHOD}

Three NC nickel alloys were fabricated by electrodeposition via the direct-LIGA lithographic micromolding process with varying solute content: nominally pure $\mathrm{Ni}$ deposited in a Watts bath, ${ }^{[38]} \mathrm{Ni}-22$ wt pet Fe, ${ }^{[39]}$ and Ni-0.5 wt pct Mn. ${ }^{[40]}$ These alloys represent different metallurgical configurations: the Watts Ni contains only trace impurities, the $\mathrm{Ni}-0.5 \mathrm{Mn}$ alloy contains $<1$ pct alloying content, ${ }^{[41]}$ while the $\mathrm{Ni}-\mathrm{Fe}$ samples contain $\geq 20$ pct alloying content. LIGA Ni alloys were deposited in a cantilever geometry for fatigue experiments (described in detail subsequently), while various dogbone specimens were also fabricated using similar dimensions for characterizing the stress-strain response. Dogbone-shaped Ni-Fe samples were electrodeposited separately in lithographically patterned molds for fatigue testing under pure tensile stresses. These dogbone samples were $10-\mu \mathrm{m}$ thick with a gage length of $2000 \mu \mathrm{m}$ and a gage width of $1000 \mu \mathrm{m}$.

As-deposited grain size distributions are shown in Figure 1, revealing that the average grain sizes of the alloys are $42 \mathrm{~nm}(\mathrm{Ni}), 25 \mathrm{~nm}$ (Ni-22Fe), and $115 \mathrm{~nm}$ (Ni-0.5Mn). The inset in Figure 1(a) shows a grain size distribution from a $\mathrm{NC} \mathrm{Ni} \mathrm{sample} \mathrm{that} \mathrm{was} \mathrm{annealed}$ at $523 \mathrm{~K}\left(250{ }^{\circ} \mathrm{C}\right)$ for 1 hour for comparison to the as-deposited materials. The largest grains in the as-deposited $\mathrm{Ni}$ and $\mathrm{Ni}-22 \mathrm{Fe}$ are $\leq 100 \mathrm{~nm}$, while the largest grains in the as-deposited $\mathrm{Ni}-0.5 \mathrm{Mn}$ and annealed $\mathrm{Ni}$ are several hundred nanometers in size. Cross-sectional ion channeling imaging of the as-deposited grain structures for these three alloys showed homogeneous grain distributions with no evidence of grain inhomogeneity or bimodality. A representative image showing the field of view of these cross sections is given in Figure 2.

In addition to initial and annealed grain size measurements, the crystallographic texture of the as-deposited material was also characterized by X-ray diffraction (XRD). The lattice parameter for the Ni-22Fe alloy was

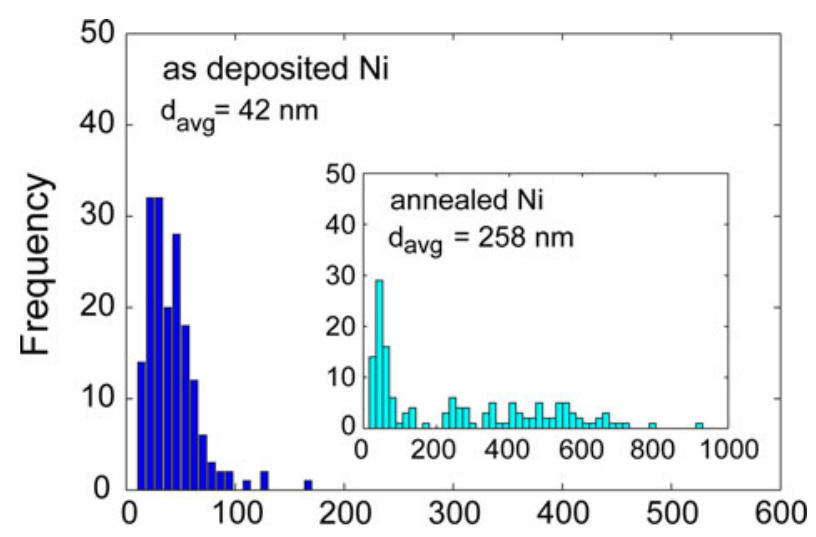

(a)
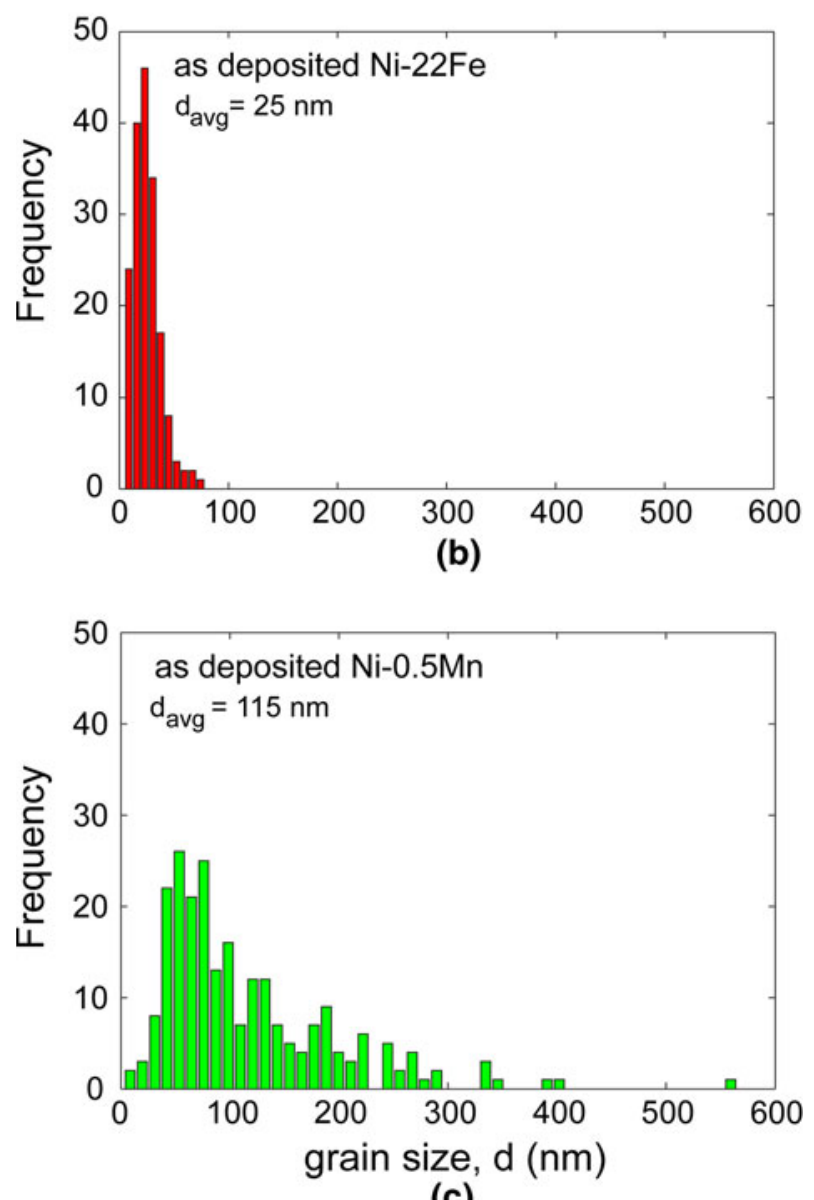

(c)

Fig. 1-Grain size distributions for as-deposited (a) Ni, (b) Ni-22Fe, and (c) Ni-0.5Mn. Inset in (a) shows distribution for annealed $\mathrm{Ni}$ sample, which was held at $250{ }^{\circ} \mathrm{C}$ for $1 \mathrm{~h}$.

$\sim 3.55 \AA$ compared to $\sim 3.52 \AA$ for $\mathrm{Ni}$ and $\mathrm{Ni}-0.5 \mathrm{Mn}$. This is consistent with larger atomic radii of $\mathrm{Fe}$ solute causing lattice expansion. (100), (110), and (111) pole figure intensities were collected for each material and integrated around the normal direction to present the textures as normalized intensity (multiple times random (MRD)) vs chi $(\chi)$, which is the angle measured from the sample normal (deposition direction), as shown in Figure 3. Nickel has an essentially random texture, while Ni-22Fe has a bimodal $\langle 111\rangle+\langle 100\rangle$ fiber texture 


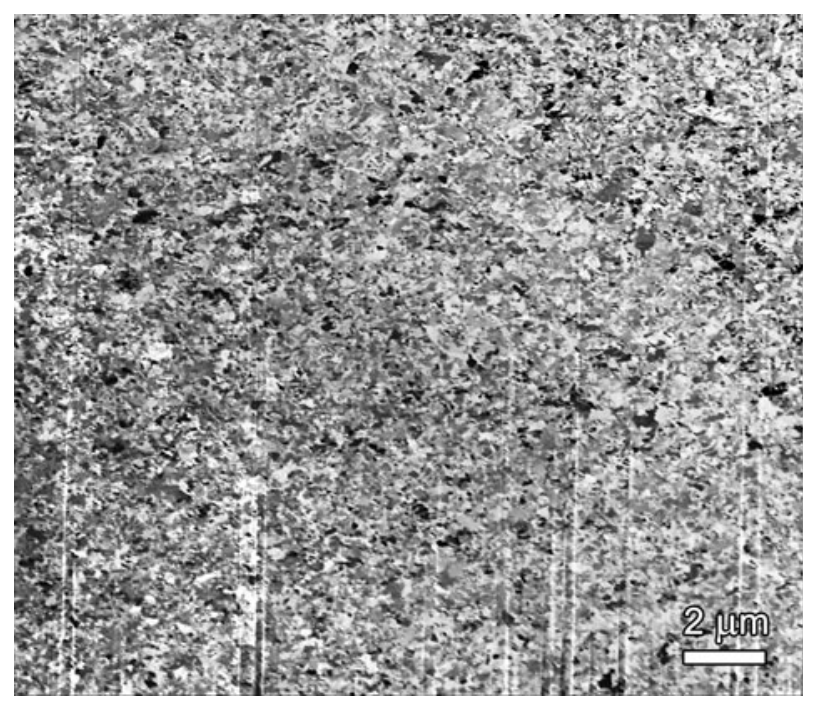

Fig. 2-Representative as-deposited grain structure of $\mathrm{Ni}-0.5 \mathrm{Mn}$. This low-magnification ion-channeling induced image of the cross section of a plated tensile bar highlights the homogeneity of the asdeposited grain structure. The other two alloys exhibited similar homogeneity in grain structure.

aligned with the deposition direction as well as a $\langle 110\rangle$ component at approximately $35 \mathrm{deg}$ from the deposition direction. By contrast, Ni-0.5Mn has a $\langle 110\rangle$ texture aligned with the deposition direction.

Fatigue lifetime experiments of the LIGA Ni alloys were performed under fully reversed bending $\left(R=\sigma_{\min } / \sigma_{\max }=-1\right)$ using a unique tapered cantilever geometry ${ }^{42]}$ producing constant peak surface stresses along a significant portion of the cantilever (Figure 4). In these lithographically patterned fatigue samples, the maximum bending stresses resulted in crack nucleation on the sidewalls of the deposition. These sidewall surfaces contained only very fine surface roughness features, on the order of the $100-\mathrm{nm}$ scale of the grain size. Due to the small size of these samples $(\sim 26-\mu \mathrm{m}$ beam width), no further attempts were made to electropolish the surfaces prior to fatigue testing. SEM imaging of sidewall crack initiation sites indicated that the native surface roughness was not a substantial contributor to crack initiation. Cyclic loading was performed under force control at a rate of $10 \mathrm{~Hz}$ using a custom built MTS servohydraulic loadframe with a $5 \mathrm{~N}$ loadcell. To investigate effects of different loading scenarios, a bending dwell test was also performed using the same bending geometry with hold times up to 3 weeks, as well as a set of Vickers dwell microindentation tests with hold times up to 8 hours. For comparison to bending fatigue experiments, tensile fatigue loading was performed on thin film Ni-Fe dogbone coupons using a piezoelectrically driven actuator capable of $1-\mu \mathrm{m}$ resolution and a loading frequency of up to $30 \mathrm{~Hz}$.

While fatigue testing was performed primarily on as-deposited material, in a separate study, each alloy was subjected to annealing treatments to determine the thermal stability of the grain structure. As-deposited samples underwent annealing in a vacuum of $10^{-3}$ torr for 1 hour at 473,623, 773, or $923 \mathrm{~K}(200,350,500$, or

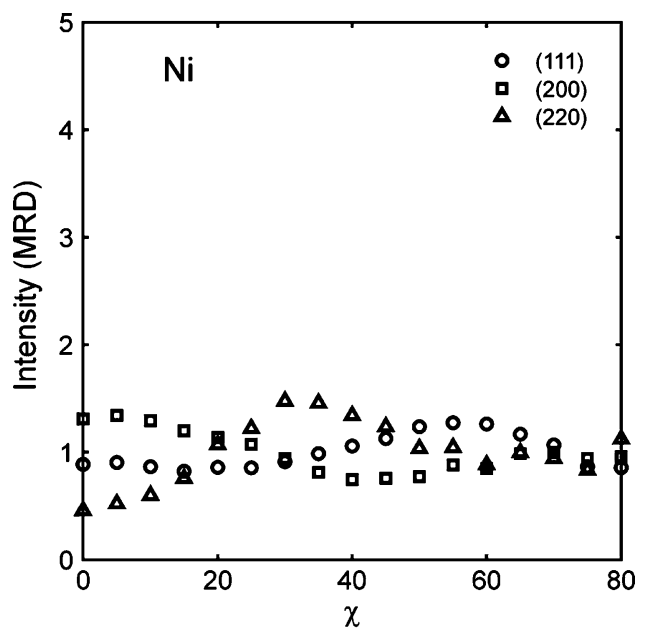

(a)

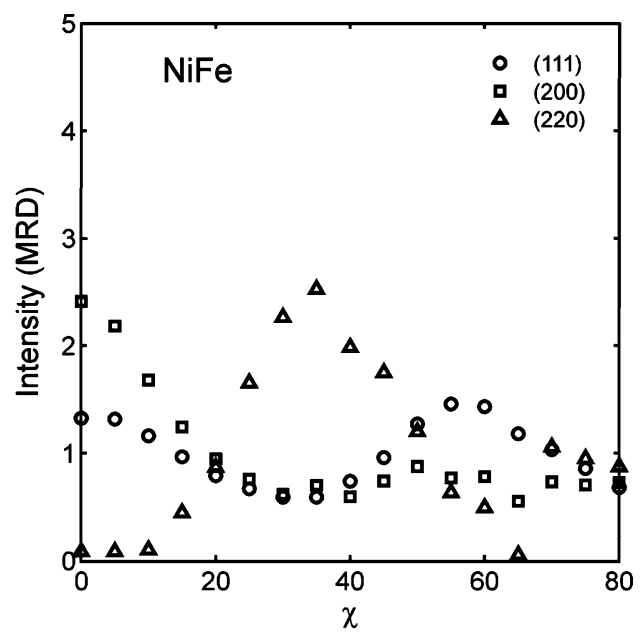

(b)

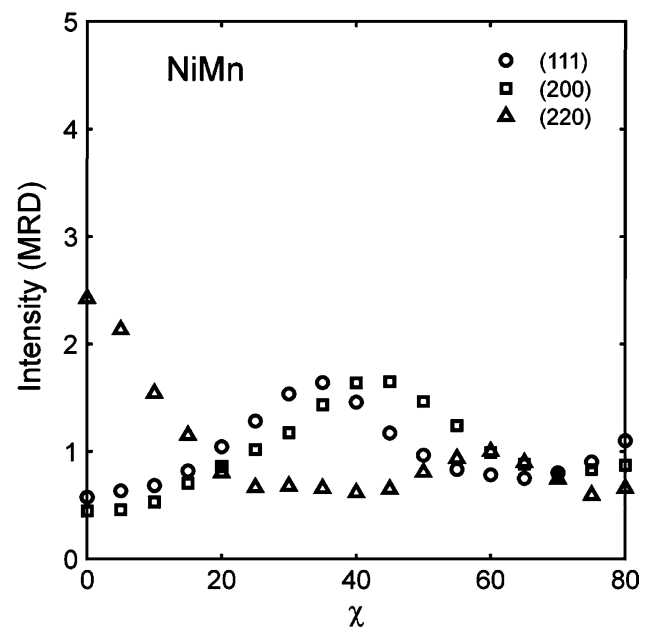

(c)

Fig. 3-As-deposited crystallographic texture of (a) Ni, (b) Ni-22, and $(c) \mathrm{Ni}-0.5 \mathrm{Mn}$ as measured by XRD. Plots show pole intensity as a function of $\chi$, the angle measured away from the sample normal (deposition) direction.

$650{ }^{\circ} \mathrm{C}$ ). Grain structures were examined by making FIB cross sections and viewing under channeling ion imaging conditions. Average grain sizes for the annealing 


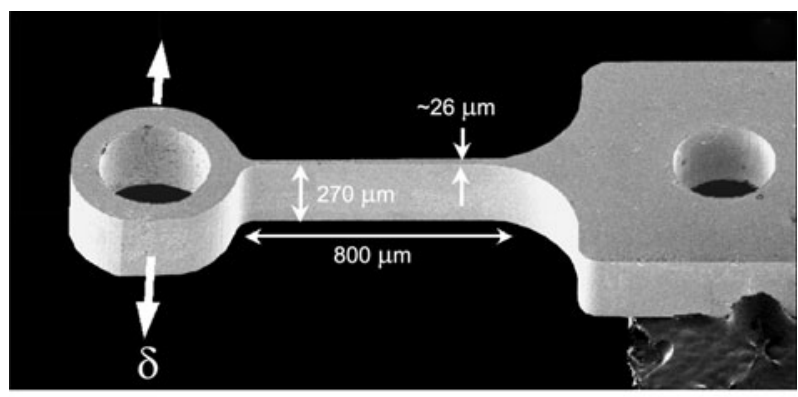

(a)

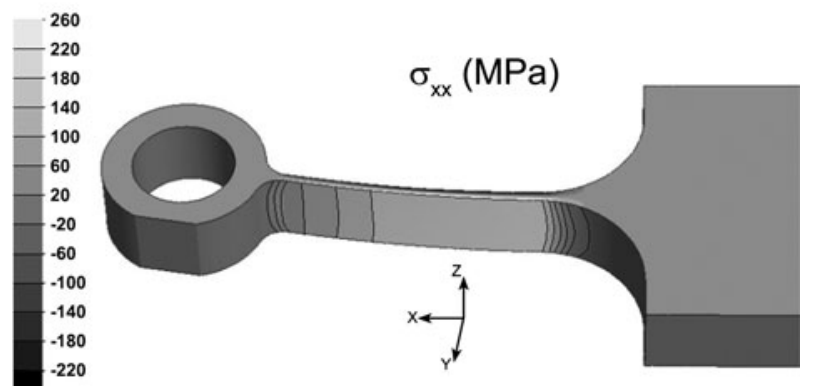

(b)

Fig. 4 - (a) Secondary electron image of the as-fabricated fatigue specimen design with critical dimensions labeled. The $26-\mu \mathrm{m}$ width tapered along the length of the gage section to produce a wide zone of constant maximum stress. (b) An elastic finite element model of the specimen configuration with an applied load of $10 \mathrm{mN}$. Image taken from Ref. 42 .

experiments were measured based on ASTM standard E 112. ${ }^{[43]}$ The results of these measurements show that $\mathrm{Ni}-0.5 \mathrm{Mn}$ is significantly more resistant to thermally driven grain growth than either $\mathrm{Ni}$ or Ni-22Fe.

Postmortem microscopy was performed on fatigue samples using FIB milling and ion channeling imaging techniques using an FEI Nova* 600 Nanolab and FEI

* Nova is a trademark of FEI, Hillsboro, OR.

Helios** Nanolab. Additionally, electron transparent

**Helios is a trademark of FEI, Hillsboro, OR.

foils were prepared using FIB milling and low $\mathrm{keV}$ cleaning for subsequent EBSD and TEM using a TECNAI $^{\dagger}$ F30 ST operating at $300 \mathrm{kV}$. FIB cross

${ }^{\dagger}$ TECNAI is a trademark of FEI, Hillsboro, OR.

sections and TEM foils were cut normal to the deposition direction (i.e., the $X-Y$ plane described in Figure 4).

\section{RESULTS}

The results of fatigue lifetime experiments for $\mathrm{NC} \mathrm{Ni}$ (yield strength, $\sigma_{y}=1300 \mathrm{MPa}$ ), Ni-0.5Mn $\left(\sigma_{y}=1200 \mathrm{MPa}\right)$, and $\mathrm{Ni}-22 \mathrm{Fe}\left(\sigma_{y}=1500 \mathrm{MPa}\right)$ are

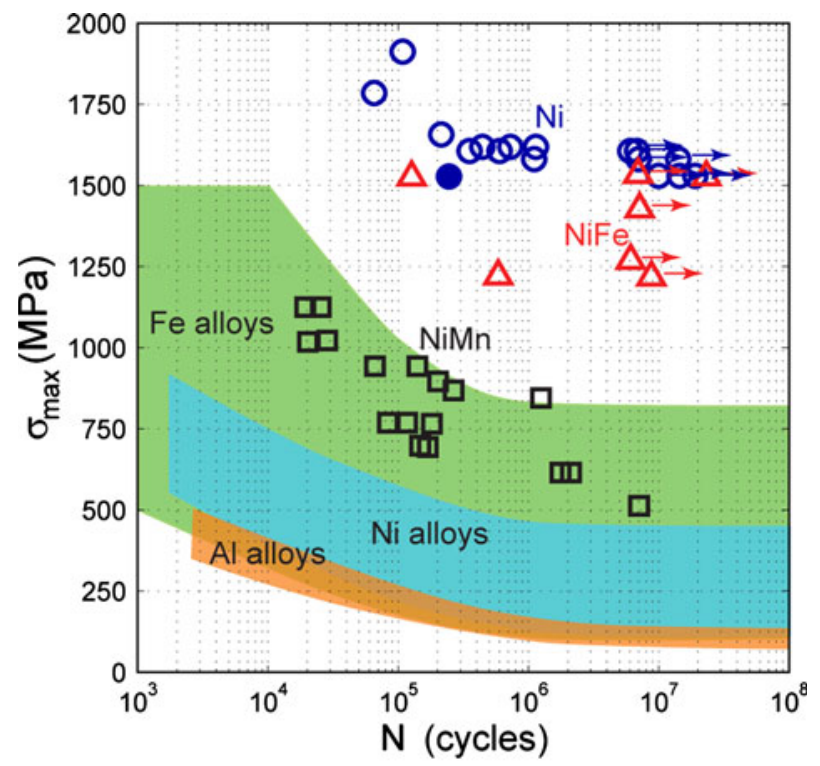

(a)

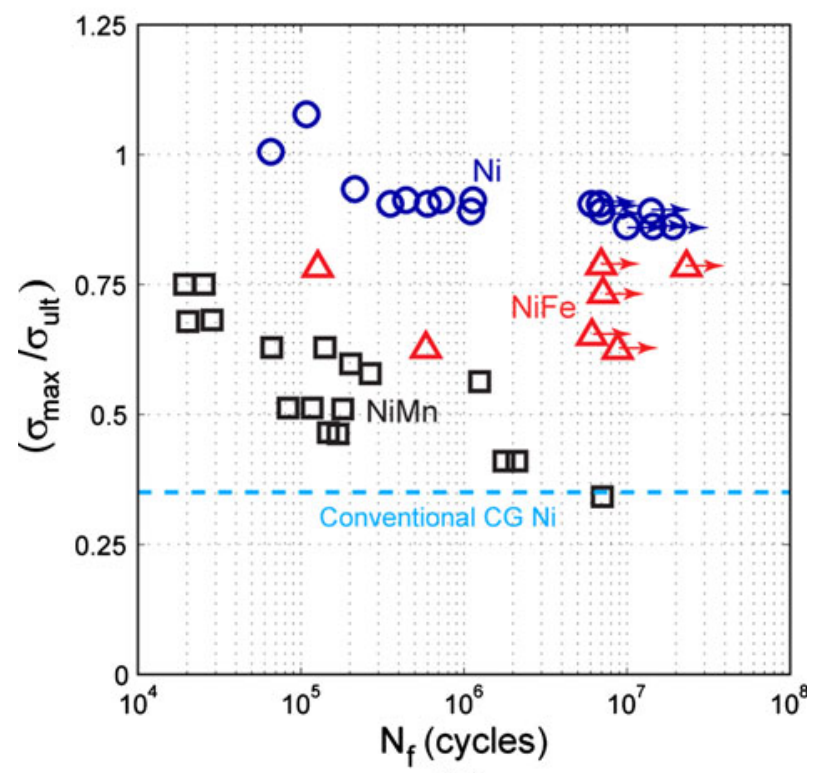

(b)

Fig. 5- (a) Fatigue lifetime plot showing performance of three NC alloys compared to conventional metals. ${ }^{[4]}$ (b) Ultimate strength normalized fatigue data for NC metals. All data in both plots were collected under fully reversed loading, $R=-1$, at $10 \mathrm{~Hz}$.

plotted as stress-life or "S-N" curves in Figure 5. The 0.2 pct yield strengths and ultimate strengths of the alloys were determined previously from tensile samples fabricated using the LIGA process. ${ }^{[44]}$ Figure 5(a) shows the number of cycles to failure as a function of the maximum stress in the fatigue cycle, whereas Figure 5(b) normalizes the maximum stress by the ultimate tensile strength. Tests in which the sample did not fail within $\sim 10^{7}$ cycles are indicated with arrows (so-called "runouts"). For comparison, Figure 5(a) includes shaded regions representing the range of fatigue behavior that exists in current conventional alloy classes. ${ }^{[4]}$ The data demonstrate that the NC alloys exhibit exceptional 
resistance to fatigue failure. While conventional alloys typically fail within $10^{4}$ to $10^{6}$ cycles when loaded at peak stresses near the yield strength, the present NC alloys can exhibit lifetimes in excess of $10^{7}$ cycles at peak stresses up to 25 pct above the nominal monotonic yield strength. This anomalous behavior is also apparent when scaling with the ultimate tensile strength (Figure 5(b)): while conventional $\mathrm{Ni}$ alloys have an endurance limit that is $\sim 35$ pct of the ultimate tensile

ॠEndurance limit is defined here as the maximum stress that does not cause failure within $10^{7}$ cycles.

strength ${ }^{[42]}$ the $\mathrm{NC} \mathrm{Ni}$ alloy, for example, has an endurance limit that is 89 pct of the ultimate tensile strength. For comparison, the HCF behavior of electrodeposited $\mathrm{Ni}$ reported by Hanlon et al. ${ }^{[11]}$ showed a scaled endurance limit of approximately 40 pct. Even without scaling, the fatigue performance of $\mathrm{Ni}$ and $\mathrm{Ni}-22 \mathrm{Fe}$ is extraordinary; at maximum stress levels of 1.5 $\mathrm{GPa}$, these materials can survive up to $10^{7}$ fatigue cycles.

If the grain size is increased, however, the exceptional fatigue resistance is diminished. The Ni sample annealed at $250{ }^{\circ} \mathrm{C}$ was tested in fatigue and is shown as a solid circle data point in Figure 5(a). The grain size distribution of this annealed sample (inset Figure 1(a)) contains a substantial fraction of grains with diameters greater than $100 \mathrm{~nm}$. At a peak stress amplitude of $1.5 \mathrm{GPa}$, the annealed $\mathrm{Ni}$ sample failed at $10^{5}$ cycles, whereas the as-deposited material had a fatigue life of $>10^{7}$ cycles at this stress level.

Fatigued samples of all three alloys show characteristic features near the crack initiation site and are examined in greater detail using FIB and TEM cross sections as well as EBSD orientation mapping. Figure 6 shows examples of fracture surfaces for a failed $\mathrm{Ni}$ sample (Figure 6(a)) and a failed $\mathrm{Ni}-22 \mathrm{Fe}$ sample (Figure 6(b)). In the vicinity of near crack initiation, there is a rough, blocky fracture morphology that transitions to a smoother surface as the fatigue crack propagated away from the initiation zone. The micronsized fractographic features in the initiation zone are much larger than the as-deposited grain size, indicating that the grain structure in the initiation zone is much different than the bulk grain structure. This is confirmed by FIB cross sectioning at each fracture initiation site. Typical grain structures from all three alloys are shown in Figure 7, with red arrows indicating aggregates of grains that have coarsened to micron-scale dimensions. White boxes in the $\mathrm{Ni}$ and $\mathrm{Ni}-22 \mathrm{Fe}$ sample indicate where EBSD orientation maps were later collected for analysis. The ion channeling conditions in Figure 7 produce contrast based on local grain orientation, and in all three materials, the as-deposited NC matrix can be seen surrounding the coarsened grain regions. Such aggregates were always found at crack initiation sites, forming groups of 10 to 30 grains spanning a region several microns in size. Also noteworthy are the elongated shapes of the coarse grains, which are most pronounced in the Ni-22Fe sample shown in Figure 7(b).
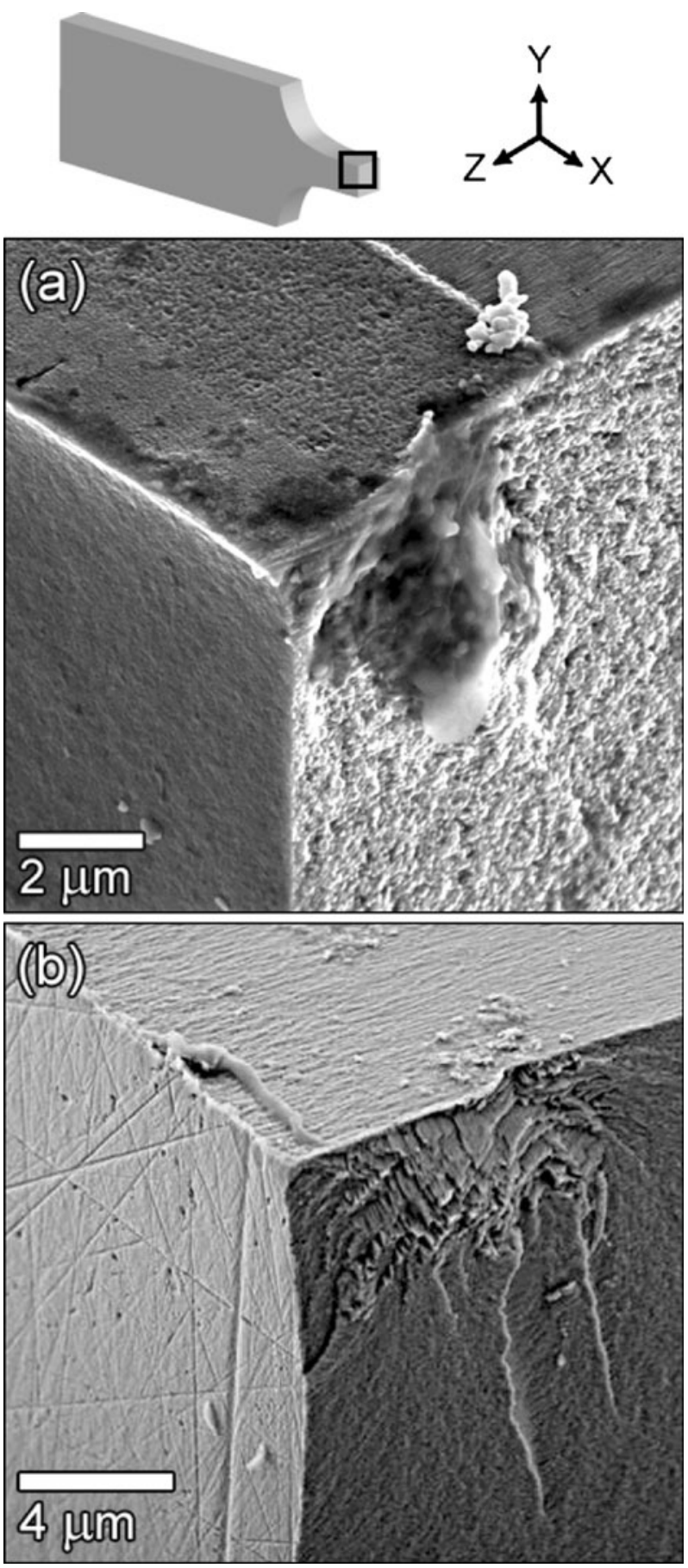

Fig. 6-Representative fracture surfaces after fatigue failure of $(a)$ $\mathrm{Ni}$ and $(b) \mathrm{Ni}-22 \mathrm{Fe}$. The fracture surface is the lower right surface, and the specimen sidewall, which is the location of maximum fiber (bending) stress, is the top surface in this perspective. In both images, coarse micron-sized features are present at the site of crack initiation on the fracture surface.

The grains are elongated preferentially along the directions of maximum shear stress, implying that grain growth is strongly influenced by the shear component of the stress tensor. Two NC Ni samples (not shown) were also fatigued to the onset of crack initiation. Visual inspection and subsequent FIB cross sections confirmed 

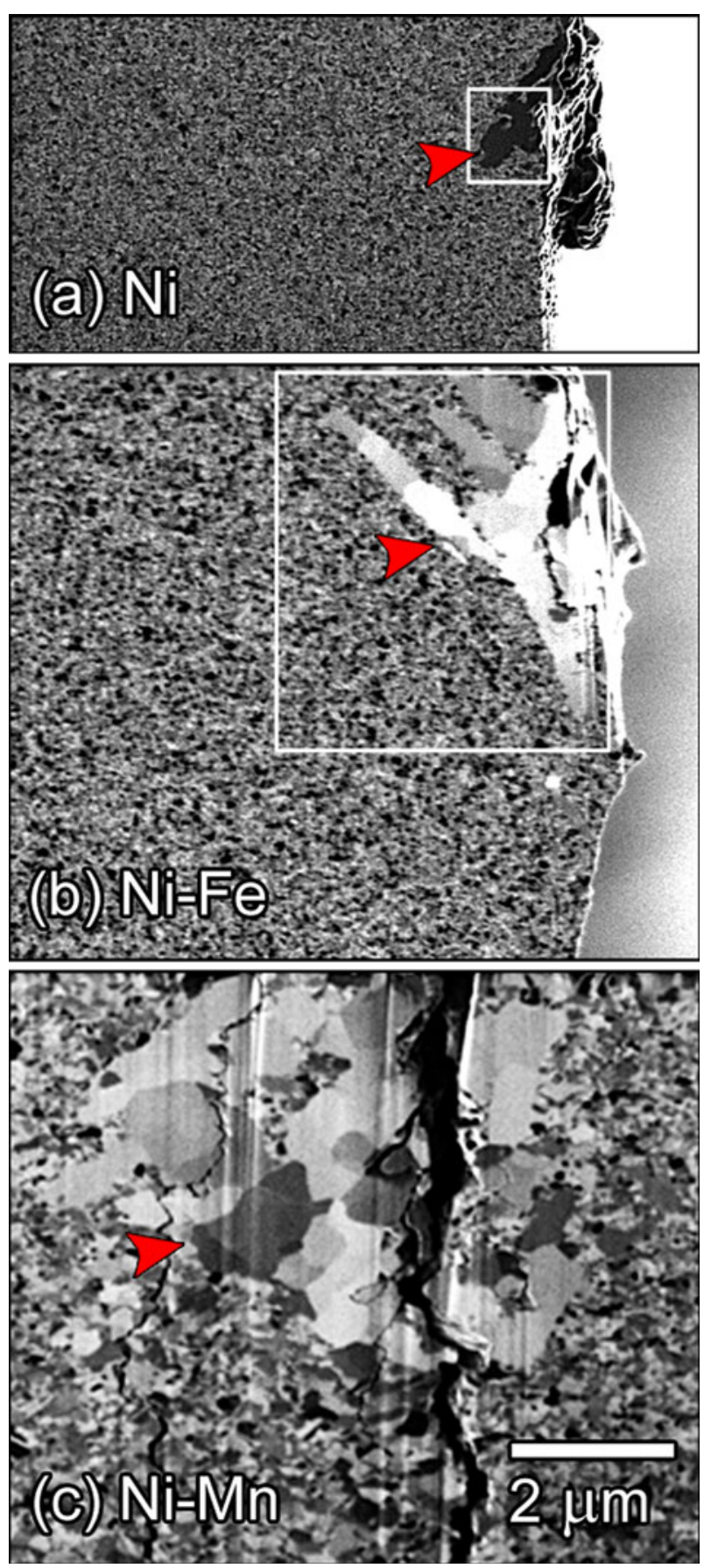

Fig. 7-Ion channeling induced images of large grains present near fatigue crack initiation sites in $(a) \mathrm{Ni},(b) \mathrm{Ni}-22 \mathrm{Fe}$, and (c) Ni-0.5Mn. Images are shown at the same scale. Red arrows denote coarse grain aggregates at crack initiation sites. The white box indicates the location of EBSD analysis in the $\mathrm{Ni}$ and $\mathrm{Ni}-22 \mathrm{Fe}$ sample.

coarse grains at the initiation site, providing additional supporting evidence of the clear tie between coarse grain formation and crack initiation.

To examine whether fatigue-induced grain growth in these alloys could also be induced by static loading, we prepared two additional experiments: a constant bending stress experiment for $\mathrm{Ni}-0.5 \mathrm{Mn}$ (the alloy which had the strongest propensity for fatigue-induced grain growth) and a sustained-load microindentation of all three NC alloys. The loading fixture from the fatigue experiments was used to apply a constant peak bending stress of $750 \mathrm{MPa}$ to an as-deposited test specimen of $\mathrm{Ni}-0.5 \mathrm{Mn}$ for 20 days $(10$ continuous days at $+750 \mathrm{MPa}$ and 10 days at $-750 \mathrm{MPa})$. This represented comparable peak stress levels and overall time duration of the experimental conditions, which resulted in the formation of coarsened grains, as shown in Figure 7(c). After holding the stress at each peak $(+/-)$ for 10 days, the sample was subsequently dissected using FIB cross sectioning to inspect for grain coarsening, but no evidence of grain growth was found. Vickers indentation was performed on all three alloys with a peak force of $0.5 \mathrm{~N}$, held constant for 8 hours. FIB cross sections underneath the indentation marks in all three $\mathrm{NC}$ alloys also showed no evidence of coarsening beneath the indentation. These results suggest that the cyclic nature of the fatigue process was responsible for grain growth, rather than a static-loading mechanism.

To complement the bulk XRD texture measurements on undeformed material, EBSD measurements on deformed specimens describe the local orientation of the coarsened grain aggregates, providing insight into how the fatigue-driven growth process affects the evolution of local crystallographic texture. Figure 8 shows orientation maps for coarse grain aggregates in (a) $\mathrm{Ni}$, (b) $\mathrm{Ni}-22 \mathrm{Fe}$, and (c) $\mathrm{Ni}-0.5 \mathrm{Mn}$ along the deposition direction $(Z)$. Coarsened $\mathrm{Ni}$ grains did not favor any particular orientation, mimicking the as-deposited untextured condition (Figure 3). Ni-0.5Mn coarse grains showed a preference for a $\langle 110\rangle$ orientation, again following the as-deposited texture. Ni-22Fe coarse grains, on the other hand, showed a strong $\langle 110\rangle$ orientation, which had been conspicuously absent from the as-deposited texture. In addition, along the principle stress $(X)$ direction, those coarsened Ni-22Fe grains possessed a $\langle 1 \overline{1} 2\rangle$ orientation. This unique preferred texture only appeared in the coarsened Ni-22Fe grains.

The cross-sectional EBSD map shown in Figure 8(c) was extracted from a region of distributed microcracks on the fatigue surface shown in Figure 9. More careful examination of the orientation of grain $\mathrm{C}$ (Figure 8(c)) reveals a $\langle 111\rangle$ orientation along the tensile axis $(X)$ and a $\langle 110\rangle$ orientation along the deposition axis $(Z)$. Using the EBSD orientation information coupled with the morphology of the surface persistent slip extrusions, a Thompson tetrahedron can be used to confirm that the most highly stressed slip system is responsible for the surface extrusions. Figure 9 illustrates this analysis, indicating that the slip system indicated by a red arrow is on a $\{111\}$ plane coincident with the extrusion plane lying at $30 \mathrm{deg}$ to the tensile axis. The crack initiates in this $\mathrm{CG}$ region on slip extrusions that are crystallographically dictated, and as the crack begins to propagate, it reorients to the preferred mode-I crack path.

The CG crack initiation region of the $\mathrm{Ni}$ sample shown in Figures 7(a) and 8(a) was harvested for TEM analysis to examine the grain growth and cyclic deformation processes in more detail. In Figure 10(a), the original NC matrix of the $\mathrm{Ni}$ sample can be seen surrounding two coarse grains (labeled $\mathrm{A}$ and $\mathrm{B}$ in 

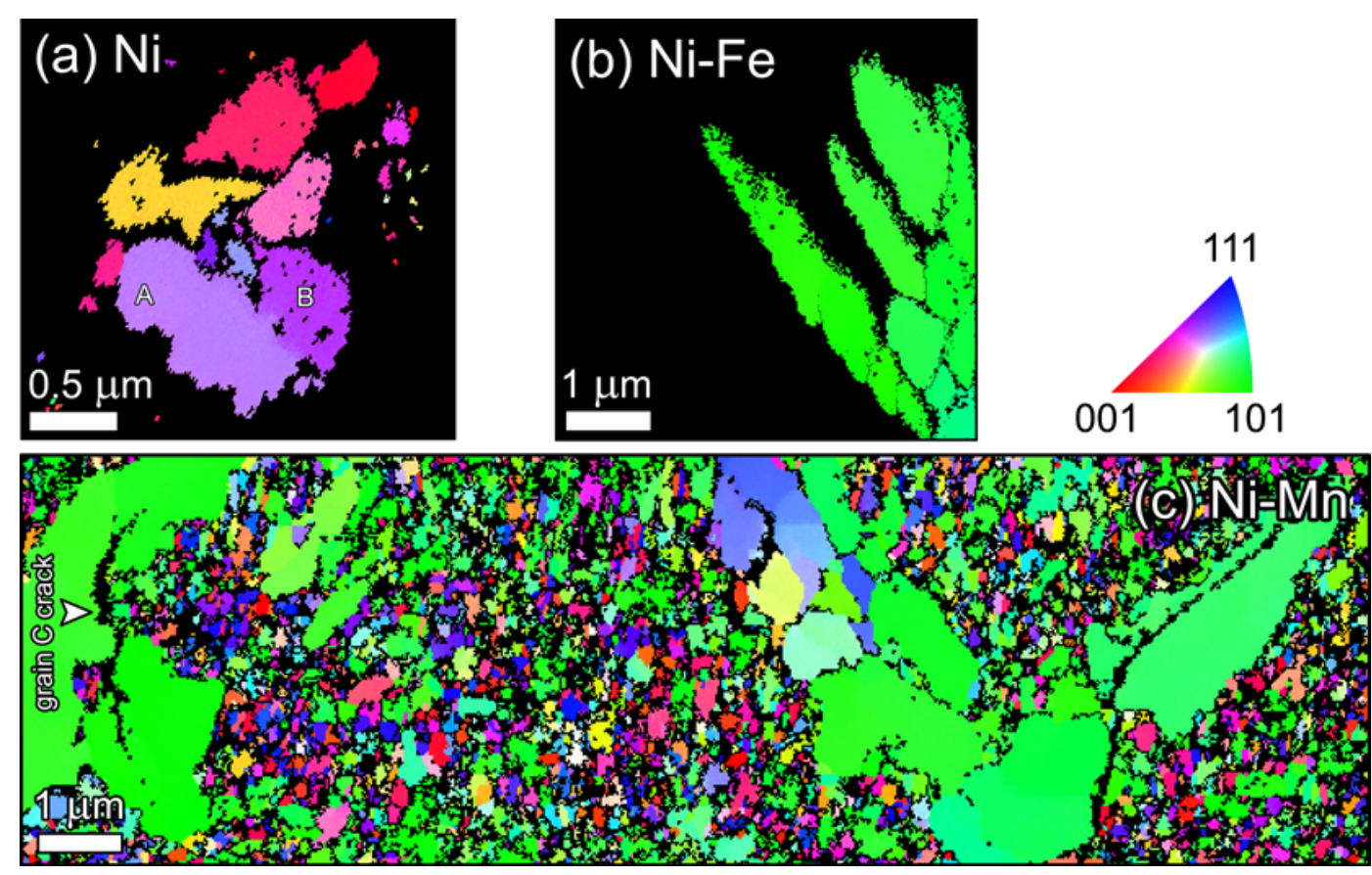

Fig. 8 - Grain orientation maps along the deposition ( $z$ ) direction in fatigued $(a) \mathrm{Ni},(b) \mathrm{Ni}-22 \mathrm{Fe}$, and $(c) \mathrm{Ni}-0.5 \mathrm{Mn}$ showing coarse grains in the fatigue crack initiation zone. The NC grain size in Ni and Ni-22Fe was too small to index using EBSD. The only sample that showed distinctly different texture in the coarse grains compared to the as-deposited state was $\mathrm{Ni}-22 \mathrm{Fe}$.
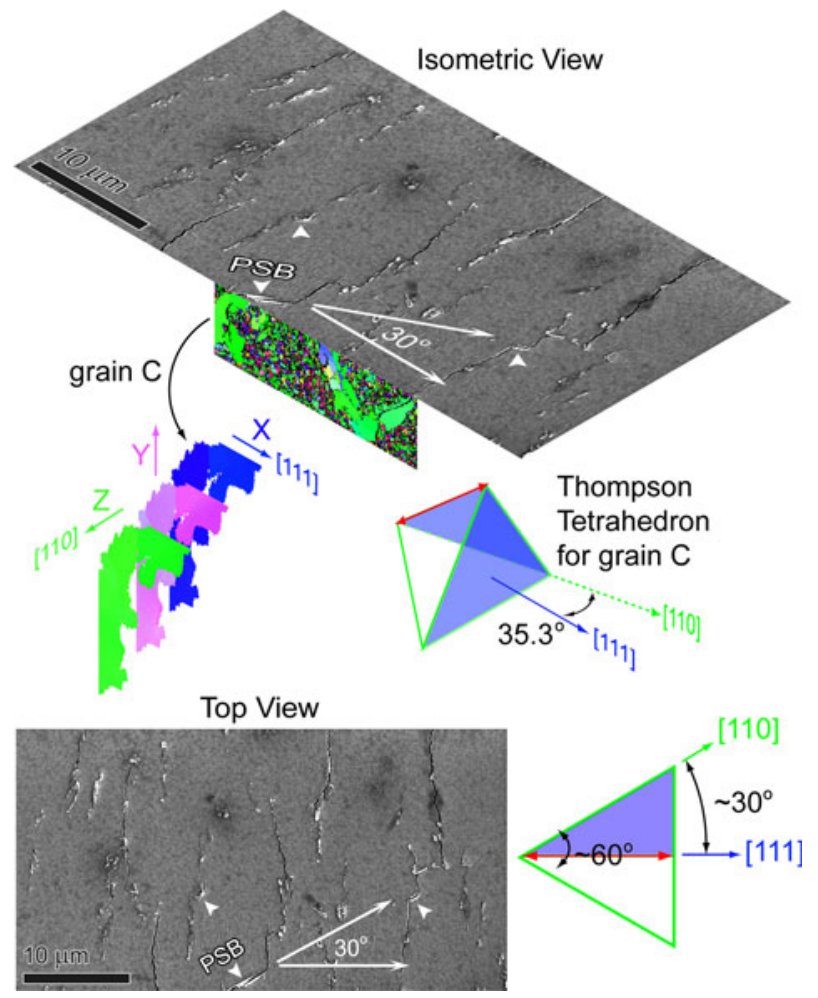

Fig. 9- (above) Isometric view of the crack initiation surface of the Ni-0.5Mn sample corresponding to the EBSD map shown in Fig. 8(c). (below) Cross-sectional EBSD maps of grain C confirm that $\{111\}$ planes coincide with extruded material located at the arrow marked "PSB" in the top view. The red arrow indicates the most likely slip direction to promote persistent slip. both Figures 8 and 10). Moderate grain growth was also observed along the crack wake (indicated by arrows in Figure 10(a)), possibly due to the high but transient stress field associated with the propagating crack front. Figure 11(b) shows a higher magnification view of the region shown by a white box in (a). Dislocations, indicated by arrows in grain A (Figure 10(b)), are accompanied by several small, isolated subgrains (indicated by circles), which are engulfed by the coarse grain. The subgrains have a close orientation relationship $(<3$ deg misorientation) to the encompassing coarse grain based on selected area diffraction patterns. The low energy nature of these boundaries explains why they would persist after absorption by the growing grain. Last, the far left boundary of grain A has a scalloped shape, indicating that the boundary maintained a distinct mobility advantage over its neighbors throughout the growth process. ${ }^{[46,47]}$

TEM micrographs of fatigued Ni-Fe tensile coupons are shown in Figure 11, showing the coarse grain aggregate at the crack initiation site. Evidence of CG aggregates in tension-tension fatigue is important, because it demonstrates that the mechanism is not dependent on the specific stress state of the test sample, as the NC LIGA samples were tested under fully reversed bending. Several of the tensile coupons were annealed at various temperatures to grow the grains and probe the fatigue behavior. One sample is shown in the cross section in Figure 11(b). This sample was annealed at $650{ }^{\circ} \mathrm{C}$ for 1 hour (resulting in grain sizes $>>1 \mu \mathrm{m}$ ) and shows traditional dislocation ladder structures associated with persistent slip in the microcrystalline 

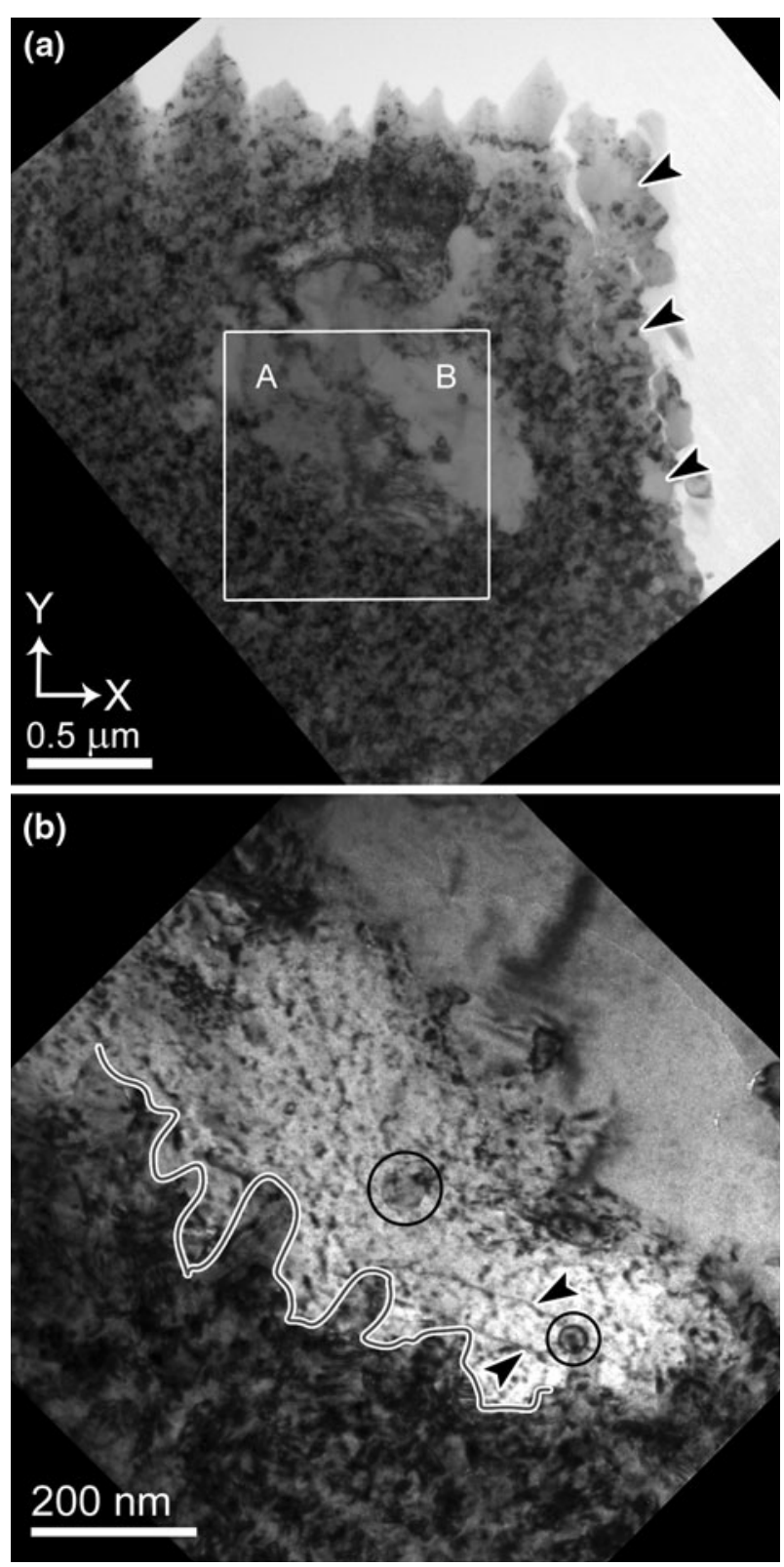

Fig. 10-TEM micrographs of Ni coarsened grains; rotated to maintain the same $X-Y$ coordinates as in Fig 9(a). (a) Bright-field imaging condition showing coarse grain aggregate embedded in the $\mathrm{NC}$ parent matrix. Moderate grain growth (indicated by arrows) is evident in the crack wake. (b) Detail of area marked in (a) showing dislocations in the grain interior (arrows), an irregular boundary (highlighted on the left), and several included grains (black circles), which are oriented within 3 deg to the parent grain.

grains near the crack wake. These collective dislocation structures occur over micron-scale dimensions and intersect the top surface of the sample at the locations shown by red arrows. At these locations, the top surface of the grain exhibits marked surface depressions, or socalled "intrusions," coincident with the dislocation pileups. The micron length scale of the dislocation structures emphasizes the fact that truly $\mathrm{NC}$ grains cannot support persistent slip, because they are not large enough to contain such arrangements.

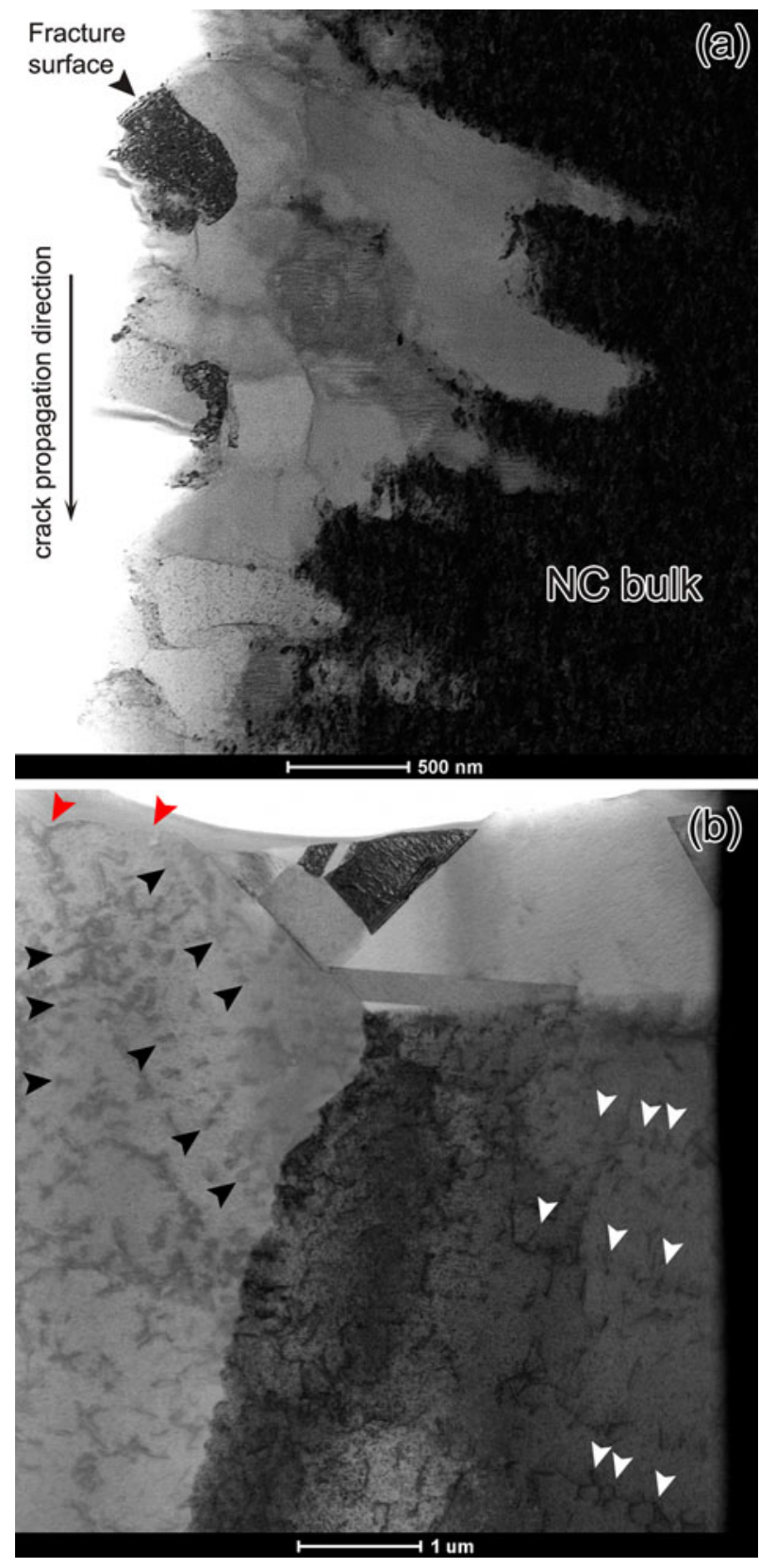

Fig. 11-TEM cross sections of (a) NC Ni-20Fe tensile fatigue sample showing coarse grains at the crack initiation site and $(b)$ annealed $\mathrm{Ni}$-20Fe fatigue sample showing PSBs (black and white arrows) in microcrystalline grains. Red arrows note locations where dislocation ladders intersect the surface.

\section{DISCUSSION}

The preceding results establish several important facts, the first of which is that these $\mathrm{NC} \mathrm{Ni}$ alloys possess exceptional fatigue resistance, with S-N behavior far exceeding existing commercial alloys. The endurance limit of $\mathrm{NC} \mathrm{Ni}$ and $\mathrm{Ni}-22 \mathrm{Fe}$ is quantitatively anomalous when scaled by the ultimate strength: whereas conventional $\mathrm{Ni}$ and its alloys typically have an endurance limit that is $\sim 35$ pct of the ultimate tensile strength, the $\mathrm{Ni}$ and $\mathrm{Ni}-22 \mathrm{Fe}$ alloys presented here exhibit endurance limits $>60$ pct of the ultimate tensile 
strength. The average grain size of these alloys is well below $100 \mathrm{~nm}$, and when stress levels are raised enough to cause failure, the fatigue process results in grain growth associated with crack initiation. TEM analysis of coarse grains suggests that the length scale of traditional dislocation-based mechanisms such as PSBs requires several hundreds of nanometers or even microns to operate. The fatigue behavior of these alloys represents an interruption of traditional fatigue failure processes analogous to the breakdown in Hall-Petch scaling associated with transitions in dislocation mechanisms. ${ }^{[18]}$

The importance of small grain size in achieving high fatigue performance is demonstrated most clearly by comparing the performance of $\mathrm{NC} \mathrm{Ni}$ and $\mathrm{NC} \mathrm{Ni-22Fe}$ to the $\mathrm{Ni}-0.5 \mathrm{Mn}$ and annealed $\mathrm{Ni}$ alloys. While the maximum grain sizes of the former are approximately 150 and $75 \mathrm{~nm}$, respectively, the $\mathrm{Ni}-0.5 \mathrm{Mn}$ and annealed $\mathrm{Ni}$ alloys contain grains several hundred nanometers in size. Grains this large located in regions of maximum stress would be more susceptible to persistent slip because of their ability to sustain collective dislocation structures necessary to form surface intrusions and extrusions. A more subtle point is that both the $\mathrm{Ni}$ $0.5 \mathrm{Mn}$ alloy and annealed $\mathrm{Ni}$ fatigue samples showed distributed microcracking, whereas the $\mathrm{NC} \mathrm{Ni}$ and $\mathrm{NC}$ $\mathrm{Ni}-22 \mathrm{Fe}$ only contained a single crack. The presence of multiple microcracks points to the fact that many regions in the material were similarly susceptible to crack initiation. While the $\mathrm{NC}$ grained materials may suppress the traditional crack initiation process, this fine grain structure offers little resistance to subsequent crack propagation. Once a single crack initiated in a NC alloy, the flaw would propagate and cause failure before any other coarsening and initiation could occur.

The present observations also suggest that grain stability is an important factor affecting the crack initiation and propagation process in these $\mathrm{NC}$ alloys. The schematic shown in Figure 12 describes a conceptual process leading to crack initiation in these NC metals. Material with an initial grain size distribution below $\sim 100 \mathrm{~nm}$ undergoes (a) cyclic loading, which leads to the growth of an aggregate of large grains (b). These coarse grains are large enough to support the to-and-fro motion of dislocations without the interference of grain boundaries, which allows PSBs (c) to initiate a crack (d). Once the fatigue crack has grown through the coarse grains, it propagates unencumbered through the NC matrix due to limited crack-tip plasticity and tortuosity. ${ }^{[4,12]}$ This model of the fatigue process implies that improvements in fatigue performance of NC metals hinges on stabilizing the grain boundaries against this growth process.

\section{A. Adiffusional Grain Growth}

Grain growth is typically thought of as a diffusive thermally activated process. Most metals and alloys are stable at low homologous temperatures due to limited diffusional boundary mobility, which decreases exponentially with decreasing temperature. ${ }^{[48]}$ An estimate of grain boundary velocity supports this assertion: in

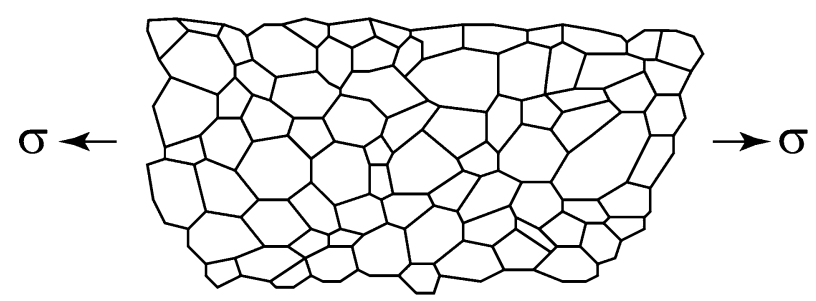

(a)

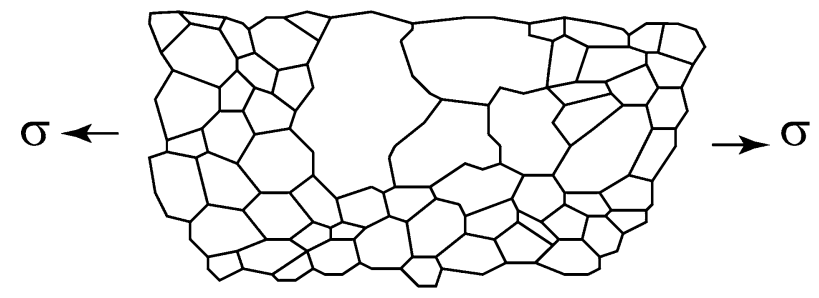

(b)

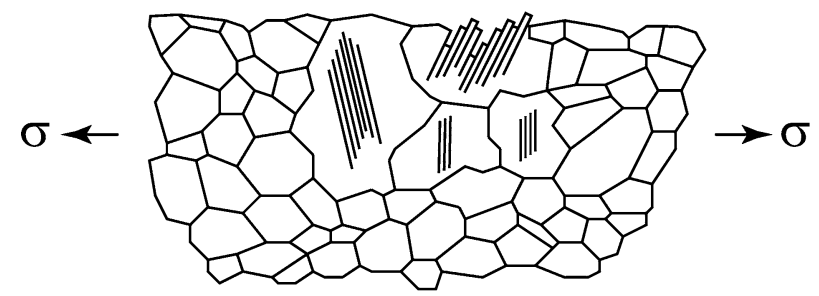

(c)

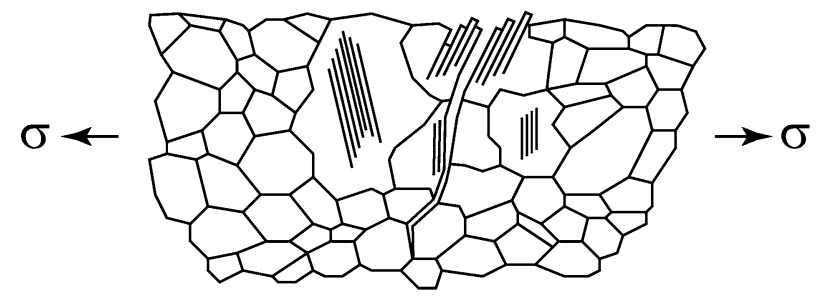

(d)

Fig. 12-Schematic illustrating the apparent fatigue-crack initiation mechanism observed in these NC Ni-based alloys. (a) Cyclic fatigue stresses are applied to a homogeneous NC starting grain structure, (b) localized clusters of coarsened grains are formed at the surface of maximum stress, $(c)$ traditional persistent slip processes can proceed in coarsened grains, and $(d)$ a fatigue crack initiates in the coarsened grains and propagates into the parent $\mathrm{NC}$ material. A modest degree of coarsening can be observed on the flanks of the propagating crack.

aluminum, ${ }^{[49]}$ for example, the estimated velocity of nanoscale grain boundaries drops from $40 \mu \mathrm{m} / \mathrm{s}$ at $0.7 T_{m}$ to only $10^{-9} \mu \mathrm{m} / \mathrm{s}$ at room temperature.

The existence of athermal grain growth in NC metals is supported by observation of coarsening at cryogenic temperatures $^{[31]}$ and by many other observations at ambient temperatures. ${ }^{[14,28,29,50,51]}$ Molecular dynamics studies on $\mathrm{Ni}$ grain boundaries has predicted that $\sim 25$ pct of the grain boundary types can undergo nonthermally activated motion. ${ }^{[52]}$ In the present investigation, there is indirect evidence that athermal coarsening may be present in the NC Ni alloys; of the three alloys considered in this study, the Ni-0.5Mn exhibited 
the least resistance to fatigue-induced grain growth even though this same alloy showed the best resistance to annealing-induced grain growth.

Stress-driven boundary motion has been observed experimentally, ${ }^{[29-31,50,53,54]}$ as well as predicted by simulations ${ }^{[33,34]}$ and theory. ${ }^{[55]}$ Recent experimental results by Rupert et al. ${ }^{[30]}$ confirmed much of this theory in NC aluminum, although for monotonic tensile stresses. Independent simulations ${ }^{[33]}$ predict that elastic stresses result in a significant driving force for boundary motion even greater than if plasticity occurs concomitantly. In such cases, stored elastic strain energy can exceed the local curvature driving force, resulting in rippled boundaries during grain growth, qualitatively similar to the wavy grain boundary shown in Figure 10. The elongated nature of the grains along directions of maximum shear, most evident in the $\mathrm{Ni}-22 \mathrm{Fe}$ example in Figure $8(\mathrm{~b})$, is further evidence indicating that the shear component of the stress tensor is important to the coarsening process.

The observed mechanically induced grain growth process may be related to the well-known process of dynamic recrystallization (DRX); however, there are several features of the microstructural evolution that distinguish the observed phenomenon from DRX. Grains that have dynamically recrystallized have been observed due to high temperature fatigue in $\mathrm{Ni}^{[56]}$ with similar boundary shapes (serrated grain boundaries and preferential growth along planes of maximum shear stress). However, the present experiments were run at room temperature (homologous temperature $T<$ $0.2 T_{m p}$ ), whereas previous work on the DRX process is associated with much higher homologous temperatures $\left(T>0.4 T_{m p}\right)$. Dynamic recrystallization also typically involves the nucleation of new grains through the formation of high-angle subgrain boundaries. This process necessarily involves the formation of dislocation cells, a collective process that is not possible due to the extremely fine starting grain size of these $\mathrm{Ni}$ alloys. Therefore, the presently observed room-temperature fatigue-induced grain evolution appears fundamentally distinct from the DRX process.

Well-established metallurgical principles of grain stabilization against normal grain growth suggest that the incorporation of either pinning particles or solute content will impede boundary motion; however, current research on this exact phenomenon in $\mathrm{NC}$ metals suggests something quite different, that solute encourages abnormal grain growth. ${ }^{[57]}$ The three alloys examined in this study represent three distinct metallurgical scenarios in this regard: Ni with only impurity content, $\mathrm{Ni}-0.5 \mathrm{Mn}$ with a small solute content, and $\mathrm{Ni}-22 \mathrm{Fe}$ with a large solute content. Ordering of these metals by alloy content, however (Ni, Ni-0.5Mn, Ni-22Fe), does not correspond to their vulnerability to fatigue-induced coarsening (Ni-0.5Mn, Ni-22Fe/Ni). More detailed analysis of the effect of impurity content, which is beyond the scope of the work presented here, may shed light on this issue.

Grain orientation can also have profound effects on growth behavior, ${ }^{[52,58]}$ from elastic mismatch accentuating the elastic driving force ${ }^{[33]}$ to causing local variations in boundary mobility. ${ }^{[59]}$ Comparison between the asdeposited and evolved coarse grain textures reveals that while $\mathrm{Ni}$ and $\mathrm{Ni}-0.5 \mathrm{Mn}$ coarse grains maintain the parent texture, $\mathrm{Ni}-22 \mathrm{Fe}$ coarse grains develop a preferred $\langle 110\rangle$ texture along the $Z$ direction, which is notably absent from the as-deposited texture (Figure 3). In the $\mathrm{NC} \mathrm{Ni}$ and $\mathrm{Ni}-0.5 \mathrm{Mn}$ alloys, texture does not appear to play as strong a role in the boundary mobility. Inspection of the EBSD patterns for the $\mathrm{Ni}-22 \mathrm{Fe}$ coarsened grains also reveals that the grains have the $\langle 1 \overline{1} 2\rangle$ pole aligned with the stress axis ( $X$ direction). This texture happens to be the well-known orientation that any fcc single crystal rotates toward during uniaxial deformation $^{[60]}$ to take full advantage of available slip systems. NC grains in these experiments would behave quite differently than a single crystal under uniaxial tension, although collective grain rotation was observed in both experiments and simulation. ${ }^{[7,35,61-64]}$ Evidence of this is suggested by the grain orientation map for Ni$22 \mathrm{Fe}$ (Figure 8(b)). Examination of the elongated coarse grains reveals that they contain several low-angle subboundaries, which may be remnants of smaller grains. This structure is reminiscent of a mechanism suggested by experiments ${ }^{[7]}$ and simulation ${ }^{[61,65]}$ in which neighboring grains under an external stress rotate to a common orientation, eliminating high-angle grain boundaries between them and allowing collective dislocation mechanisms to occur. Unfortunately, a clear conclusion on this topic cannot yet be drawn from the available data, and additional work is needed to identify the precise mechanism of fatigue-induced grain growth in all three alloys.

\section{B. Future Work}

There are several questions that these experiments raise that cannot yet be fully answered. One issue is whether locally coarsened grains form in uncracked specimens. The presence of cracks provides a fiduciary mark pointing to the location of coarse grain regions, but without such a means to find these grains, the search for CG aggregates becomes a "needle-in-a-haystack" exercise. In an effort to survey large regions of material for coarsening prior to failure, other methods of inspection are possible including the use of XRD. Such a study, however, is beyond the scope of this work. Another question to be answered by additional research is whether there is a threshold stress amplitude below which the coarsening process does not occur. The present results do suggest the existence of such a threshold for grain growth; such a threshold stress may be the source of the observed endurance limit in the absence of dislocation-induced thresholds. Further study is also necessary to understand why cyclic loading drives the growth process, while similar levels of static stresses do not. There is experimental evidence of cyclically driven local coarsening in ultra-fine-grained $\mathrm{Cu}^{[66]}$ and NC-twinned $\mathrm{Cu} ;{ }^{[32]}$ however, in those cases, there was no evidence of anomalous fatigue performance. In neither this study nor other local coarsening studies does there emerge a clear mechanism distinction between cyclically driven and monotonically driven coarsening. 


\section{CONCLUSIONS}

In conclusion, we have examined three $\mathrm{NC} \mathrm{Ni}$ alloys in high-cycle fatigue and found evidence of exceptional, quantitatively anomalous performance. The most striking result is the apparent suppression of fatigue crack nucleation and failure by prevention of collective dislocation slip through the preservation of a $\mathrm{NC}$ grain structure. In cases when the stress is increased, leading to failure, thorough examination reveals that crack initiation is always preceded by the formation of a region of highly coarsened grains. Postmortem microscopy of these coarsened regions appears consistent with published literature, which suggests an adiffusional shear stress driven growth process. Analysis of several fatigued samples indicates a potential mechanism for fatigue failure in which grains coarsen to a size that supports collective dislocation activity, allowing PSBs to initiate a fatigue crack. Once the crack traverses the tougher, coarsened grains, the less ductile NC matrix presents little propagation resistance.

\section{ACKNOWLEDGMENTS}

The authors thank Drs. T.R Christensen and S.H. Goods for supplying the various electroplated alloys used in this investigation, as well as Dr. E.A. Holm for helpful discussions and guidance regarding grain growth phenomenon. The authors also thank Dr. P.G. Kotula, Dr. B.G. Clark, Dr. J.R. Michael, M. Rye, and B. McKenzie for electron microscopy support, as well as Dr. M. Rodriguez for XRD support. This work was performed, in part, at the Center for Integrated Nanotechnologies, a United States Department of Energy, Office of Basic Energy Sciences, user facility. This work was funded by the United States Department of Energy, Office of Basic Energy Sciences, Division of Materials Sciences and Engineering. Sandia is a multiprogram laboratory operated by Sandia Corporation, a Lockheed Martin Company, for the United States Department of Energy's National Nuclear Security Administration under Contract No. DE-AC04-94AL85000.

\section{REFERENCES}

1. W. Schutz: Eng. Fract. Mech., 1996, vol. 54 (2), pp. 263-300.

2. H. Gleiter: Prog. Mater. Sci., 1989, vol. 33 (4), pp. 223-315.

3. A.S. Khan, Y.S. Suh, X. Chen, L. Takacs, and H.Y. Zhang: Int. J. Plast., 2006, vol. 22 (2), pp. 195-209.

4. K.S. Kumar, H. Van Swygenhoven, and S. Suresh: Acta Mater., 2003, vol. 51 (19), pp. 5743-74.

5. S.R. Agnew, B.R. Elliott, C.J. Youngdahl, K.J. Hemker, and J.R. Weertman: Mater. Sci. Eng. A, 2000, vol. A285 (1-2), pp. 391-96.

6. L. Lu, M.L. Sui, and K. Lu: Science, 2000, vol. 287 (5457), pp. 1463-66.

7. D. Jia, K.T. Ramesh, and E. Ma: Acta Mater., 2003, vol. 51 (12), pp. 3495-3509.

8. L. Ajdelsztajn, B. Jodoin, and J.M. Schoenung: Surf. Coat. Technol., 2006, vol. 201 (3-4), pp. 1166-72.

9. A.A. Karimpoor and U. Erb: Phys. Status Solidi A, 2006, vol. 203 (6), pp. 1265-70.

10. Y. Yang, B. Imasogie, G.J. Fan, P.K. Liaw, and W.O. Soboyejo: Metall. Mater. Trans. A, 2008, vol. 39A, pp. 1145-56.
11. T. Hanlon, Y.N. Kwon, and S. Suresh: Scripta Mater., 2003, vol. 49 (7), pp. 675-80.

12. T. Hanlon, E.D. Tabachnikova, and S. Suresh: Int. J. Fatigue, 2005, vol. 27 (10-12), pp. 1147-58.

13. G.J. Fan, L.F. Fu, G.Y. Wang, H. Choo, P.K. Liaw, and N.D. Browning: J. Alloys Compd., 2007, vols. 434-435, pp. 298-300.

14. A.B. Witney, P.G. Sanders, J.R. Weertman, and J.A. Eastman: Scripta Metall. Mater., 1995, vol. 33 (12), pp. 2025-30.

15. Y. Yang, B.I. Imasogie, S.M. Allameh, B. Boyce, K. Lian, J. Lou, and W.O. Soboyejo: Mater. Sci. Eng. A, 2007, vol. 444 (1-2), pp. $39-50$.

16. E.O. Hall: Nature, 1954, vol. 173 (4411), pp. 948-49.

17. N.J. Petch: J. Iron Steel Inst., 1953, vol. 174 (1), pp. 25-28.

18. M.A. Meyers, A. Mishra, and D.J. Benson: Prog. Mater. Sci., 2006, vol. 51 (4), pp. 427-556.

19. K.S. Kumar, S. Suresh, M.F. Chisholm, J.A. Horton, and P. Wang: Acta Mater., 2003, vol. 51 (2), pp. 387-405.

20. J. Schiotz and K.W. Jacobsen: Science, 2003, vol. 301 (5638), pp. $1357-59$.

21. H. Van Swygenhoven: Mater. Sci. Eng. A, 2008, vol. 483, pp. 33-39.

22. X.Y. Li, Y.J. Wei, L. Lu, K. Lu, and H.J. Gao: Nature, 2010, vol. 464 (7290), pp. 877-80.

23. B.T. Ma and C. Laird: Acta Metall., 1989, vol. 37 (2), pp. 325-36.

24. H. Conrad: Mater. Sci. Eng. A, 2003, vol. 341 (1-2), pp. 216-28.

25. K.S. Chan: Metall. Mater. Trans. A, 2003, vol. 34A, pp. 43-58.

26. H.A. Padilla and B.L. Boyce: Exp. Mech., 2010, vol. 50 (1), pp. $5-23$.

27. Y. Estrin and A. Vinogradov: Int. J. Fatigue, 2010, vol. 32 (6), pp. 898-907.

28. V.Y. Gertsman and R. Birringer: Scripta Metall. Mater., 1994, vol. 30 (5), pp. $577-81$

29. D.S. Gianola, S.V. Petegem, M. Legros, S. Brandstetter, H.V. Swygenhoven, and K.J. Hemker: Acta Mater., 2006, vol. 54 (8), pp. 2253-63.

30. T.J. Rupert, D.S. Gianola, Y. Gan, and K.J. Hemker: Science, 2009, vol. 326 (5960), pp. 1686-90.

31. K. Zhang, J.R. Weertman, and J.A. Eastman: Appl. Phys. Lett., 2005, vol. 87 (6), p. 061921.

32. C.J. Shute, B.D. Myers, S. Xie, T.W. Barbee, Jr., A.M. Hodge, and J.R. Weertman: Scripta Mater., 2009, vol. 60 (12), pp. 107377.

33. C.C. Battaile, W.A. Counts, G.W. Wellman, T.E. Buchheit, and E.A. Holm: Metall. Mater. Trans. A, 2007, vol. 38A, pp. 2513-22.

34. H. Zhang, M.I. Mendelev, and D.J. Srolovitz: Acta Mater., 2004, vol. 52 (9), pp. 2569-76.

35. D. Farkas, S. Mohanty, and J. Monk: Mater. Sci. Eng. A, 2008, vol. 493A, pp. 33-40.

36. J. Monk and D. Farkas: Phys. Rev. B, 2007, vol. 75 (4), p. 045414.

37. J. Schiøtz: Mater. Sci. Eng. A, 2004, vols. 375-377, pp. 975-79.

38. T.E. Buchheit, D.A. LaVan, J.R. Michael, T.R. Christenson, and S.D. Leith: Metall. Mater. Trans. A, 2002, vol. 33A, pp. 539-54.

39. T.E. Buchheit, S.H. Goods, P.G. Kotula, and P.F. Hlava: Mater. Sci. Eng. A, 2006, vol. 432 (1-2), pp. 149-57.

40. J.J. Kelly, S.H. Goods, and N.Y.C. Yang: Electrochem. Solid State Lett., 2003, vol. 6 (6), pp. C88-C89.

41. A.A. Talin, E.A. Marquis, S.H. Goods, J.J. Kelly, and M.K. Miller: Acta Mater., 2006, vol. 54 (7), pp. 1935-47.

42. B.L. Boyce, J.R. Michael, and P.G. Kotula: Acta Mater., 2004, vol. 52 (6), pp. 1609-19.

43. Standard Test Methods for Determining Average Grain Size, ASTM International, West Conshohocken, PA, 2004.

44. S. Goods: Private communication, Sandia National Laboratories, Livermore, CA, 2010

45. H.E. Boyer, ed.: Atlas of Fatigue Curves, ASM, Metals Park, OH, 1986.

46. N.M. Hwang: J. Mater. Sci., 1998, vol. 33 (23), pp. 5625-29.

47. P.R. Rios: Scripta Mater., 1998, vol. 38 (9), pp. 1359-64.

48. G. Gottstein, D.A. Molodov, and L.S. Shvindlerman: Interface Sci., 1998, vol. 6 (1-2), pp. 7-22.

49. M. Winning, G. Gottstein, and L.S. Shvindlerman: Acta Mater., 2001, vol. 49 (2), pp. 211-19.

50. X.Z. Liao, A.R. Kilmametov, R.Z. Valiev, H.S. Gao, X.D. Li, A.K. Mukherjee, J.F. Bingert, and Y.T. Zhu: Appl. Phys. Lett., 2006, vol. 88 (2), p. 021909. 
51. M. Legros, D.S. Gianola, and K.J. Hemker: Acta Mater., 2008, vol. 56 (14), pp. 3380-93.

52. D.L. Olmsted, E.A. Holm, and S.M. Foiles: Acta Mater., 2009, vol. 57 (13), pp. 3704-13.

53. J. Washburn and E.R. Parker: Trans. Am. Inst. Min. Metall. Eng., 1952, vol. 194 (10), pp. 1076-78.

54. C.H. Li, E.H. Edwards, J. Washburn, and E.R. Parker: Acta Metall., 1953, vol. 1 (2), pp. 223-29.

55. J.W. Cahn, Y. Mishin, and A. Suzuki: Acta Mater., 2006, vol. 54 (19), pp. 4953-75.

56. S. Chen and G. Gottstein: Acta Metall., 1988, vol. 36 (12), pp. 3093-3101.

57. E.A. Holm: Private communication, Sandia National Laboratories, Albuquerque, NM, 2010.

58. D.L. Olmsted, S.M. Foiles, and E.A. Holm: Acta Mater., 2009, vol. 57 (13), pp. 3694-3703.
59. E.A. Holm, N. Zacharopoulos, and D.J. Srolovitz: Acta Mater., 1998, vol. 46 (3), pp. 953-64.

60. G. Dieter: Mechanical Metallurgy, 3rd ed., McGraw-Hill, New York, NY, 1986.

61. A. Hasnaoui, H. Van Swygenhoven, and P.M. Derlet: Phys. Rev. B, 2002, vol. 66 (18), p. 184112.

62. A.J. Haslam, D. Moldovan, V. Yamakov, D. Wolf, S.R. Phillpot, and H. Gleiter: Acta Mater., 2003, vol. 51 (7), pp. 2097-2112.

63. Y.B. Wang, J.C. Ho, X.Z. Liao, H.Q. Li, S.P. Ringer, and Y.T. Zhu: Appl. Phys. Lett., 2009, vol. 94 (1), p. 011908.

64. D. Moldovan, D. Wolf, S.R. Phillpot, and A.J. Haslam: Acta Mater., 2002, vol. 50 (13), pp. 3397-3414.

65. D. Moldovan, V. Yamakov, D. Wolf, and S.R. Phillpot: Phys. Rev. Lett., 2002, vol. 89 (20), p. 206101.

66. H.W. Hoppel, Z.M. Zhou, H. Mughrabi, and R.Z. Valiev: Philos. Mag. A, 2002, vol. 82 (9), pp. 1781-94. 